\title{
РАДИАЦИОННО-ЭКОЛОГИЧЕСКИЙ МОНИТОРИНГ АГРОЭКОСИСТЕМ В РАЙОНЕ БЕЛОЯРСКОЙ АЭС
}

\author{
Панов Алексей Валерьевич1, \\ riar@mail.ru
}

\author{
Трапезников Александр Викторович2, \\ vera_zar@mail.ru
}
Кузнецов Владимир Константинович 1 , vkkuzn@yandex.ru

\author{
Коржавин Александр Васильевич², \\ BFS_zar@mail.ru
}

\begin{abstract}
Исамов Низаметдин Низаметдинович1, nizomis@yandex.ru
\end{abstract}

\footnotetext{
1 Всероссийский научно-исследовательский институт радиологии и агроэкологии, Россия, 249032, г. Обнинск, Киевское шоссе, 109 км.

2 Институт экологии растений и животных Уральского отделения РАН, Россия, 620144, г. Екатеринбург, ул. 8 Марта, 202.
}

\begin{abstract}
Актуальность. Поступление в окружающую среду техногенных радионуклидов при эксплуатации АЭС может привести к их аккумуляции в отдельных звеньях трофической цепи, что повлияет на формирование дозовых нагрузок на население. Сельскохозяйственная продукция и местные продукты питания, производящиеся вблизи АЭС, являются одним из основных источников поступления радионуклидов в организм человека, проживающего в районе размещения атомной электростанции. Цель: оценка современной радиационной обстановки в районе Белоярской АЭС и АО «Институт реакторных материалов» на основе созданной системы радиационно-экологического мониторинга аграрных экосистем.
\end{abstract}

Объекты. Мониторинговые исследования аграрных экосистем проведены в 2013 и 2019 ге. в 30-км зоне вокруг радиационноопасных объектов. На различном расстоянии и направлениях от них заложены контрольные участки на пашне - 15, лугопастбищных угодьях - 13 и огородах населенных пунктов - 13. На контрольных участках измеряли мощность дозы, отбирали пробы почв, продукции растениеводства, кормопроизводства и продуктов питания.

Методы. Всего исследовано в 2013 г. - 137, в 2019 г. - 94 образца. В компонентах агроэкосистем оценивали содержание ${ }^{40}$, ${ }^{226} \mathrm{Ra},{ }^{232} \mathrm{Th},{ }^{90} \mathrm{Sr},{ }^{137} \mathrm{Cs}$ u ${ }^{239,240} \mathrm{Pu}$. В сельскохозяйственной и пищевой продукции дополнительно определяли ${ }^{3} \mathrm{H} u{ }^{14} \mathrm{C}$.

Результаты. Показано, что содержание ${ }^{90} \mathrm{Sr}$ в почве агроэкосистем в районе радиационно-опасных объектов составляет 4,3...7,2 Бк/к2, ${ }^{137} \mathrm{Cs}$ варьирует в пределах 7,5...18,9 Бк/к2. Диапазон вариации содержания естественных радионуклидов со-

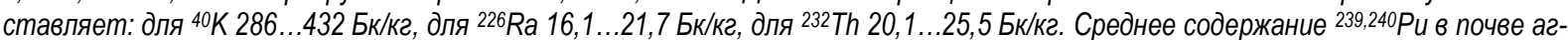
роэкосистем составило 0,13 Бк/ке при вариации 0,07...0,25 Бк/ке. Мощность дозы находилась в диапазоне 0,08...0,13 мк3в/4,

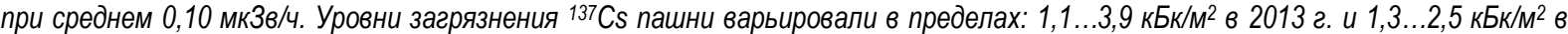
2019 г. Диапазон данных по плотностям загрязнения ${ }^{137} \mathrm{Cs}$ лугопастбищных угодий оказался шире: 1,5...4,5 кБк/м² в 2013 г. и

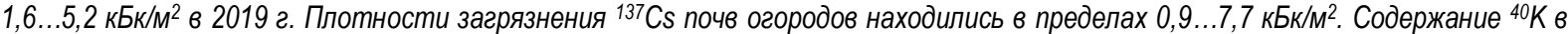
продукции растениеводства района АЭС варьировало в пределах от 48 до 526 Бк/ка, что определяется видовыми особенностями растений и характеристиками почв, где выращиваются культуры. В продукции кормопроизводства накопление ${ }^{40} \mathrm{~K}$ отмечено в диапазоне 260...543 Бк/к2, в продукции животноводства в пределах 18...97 Бк/ка. Удельная активность радионуклидов в зерне отмечена в диапазонах: для ${ }^{90} \mathrm{Sr} 1,03 \ldots 2,8$ Бк/ке, для ${ }^{137} \mathrm{Cs} 0,15 \ldots 0,94$ Бк/ке. Максимальные уровни накопления ${ }^{137} \mathrm{Cs}$ зафриксированы в ячмене $(0,94$ Бк/ке) и были ниже норматива СанПиН в 64 раза. Среди овощей, картофреля и бахчевых максимальные уровни удельной активности как ${ }^{90} \mathrm{Sr}\left(0,84\right.$ Бк/к己), так и ${ }^{137} \mathrm{Cs}(0,26$ Бк/к2) отмечались в свекле в 2013 2., однако они были ниже нормативов СанПиН в 45 и 300 раз, соответственно. В соломе зерновых среднее содержание ${ }^{90} \mathrm{Sr}$ варьировало

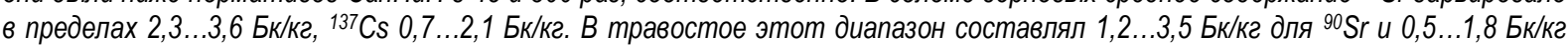
для ${ }^{137} \mathrm{Cs}$, соответственно. Максимальные уровни удельной активности ${ }^{90} \mathrm{Sr}$ в соломе (3,6 Бк/ке) оказались в 50 раз ниже норматива по содержанию этого радионуклида в кормах, по ${ }^{137} \mathrm{Cs}$ (2,1 Бк/к2) эта разнииа составила 190 раз. Максимальные уровни содержания ${ }^{90} \mathrm{Sr}$ в траве (3,5 Бк/ке) были в 14 раз ниже норматива, по ${ }^{137} \mathrm{Cs}$ (1,76 Бк/к2) почти в 56 раз. В 2013 и 2019 г2. динамика содержания техногенных радионуклидов в молоке была разнонаправленной: no ${ }^{90} \mathrm{Sr}$ оно несколько возросло, по ${ }^{137} \mathrm{Cs}$ уменьшилось. Однако даже максимальные значения удельной активности ${ }^{90} \mathrm{Sr}\left(0,41 \mathrm{Б \kappa /ת)} u^{137} \mathrm{Cs}(0,11\right.$ Бк/ת) в молоке оказались ниже граничных уровней, установленных нормативами СанПиН в 60 раз по радиостронцию и в 900 раз по радиоцезию. Нормируемое содержание ${ }^{137} \mathrm{Cs}$ в говядине $(0,12$ Бк/к2) в 2019 г. оказалось более чем в 1,5 тыс. раз ниже требований СанПиН. Показано, что ${ }^{3} \mathrm{H}$ и ${ }^{14} \mathrm{C}$ в сельскохозяйственных и пищевых продуктах в большей степени накапливаются в кормах сельскохозяйственных животных (82...255 Бк/к2), чуть меньше в продовольственном зерне (40...82 Бк/к2). Далее по степени накопления ${ }^{3} \mathrm{H}$ u ${ }^{14} \mathrm{C}$ следуют молоко и картофрель (10...95 Бк/ка) и в наименьшей степени данные радионуклиды аккумулируются в овощах (3...8 Бк/к2). Результаты радиационно-экологического мониторинга агроэкосистем показали, что многолетние нормализованные выбросы Белоярской АЭС и АО «Институт реакторных материалов» не привели к регистрируемому увеличению содержания техногенных радионуклидов в почве, сельскохозяйственной продукции и продуктах питания по сравнению с региональным фоном. Отмечена необходимость дальнейшего изучения закономерностей накопления ${ }^{3} \mathrm{H}$ и ${ }^{14} \mathrm{C}$ в сельскохозяйственной и пищевой продукции района размещения АЭС.

\section{Ключевые слова:}

Атомная электростанция, радиационная безопасность, радионуклиды, сельскохозяйственная продукция, продукты питания, радиационный контроль, почва, плотность загрязнения. 


\section{Введение}

Более чем 65-летний опыт эксплуатации АЭС в технологически штатном режиме не выявил негативного влияния атомных электростанций на человека и живые организмы (биоту). В то же время даже в условиях нормальной работы АЭС производит в строго регламентированных количествах выбросы газоаэрозолей и сбросы технологических вод, содержащих радионуклиды [1-3]. Поступление в окружающую среду техногенных радионуклидов станционного происхождения может привести к их аккумуляции в отдельных звеньях трофической цепи, что повлияет на формирование дополнительных дозовых нагрузок на население. Сельскохозяйственная продукция и местные продукты питания, производящиеся вблизи АЭС, являются одним из основных источников поступления радионуклидов в организм человека, проживающего в районе размещения атомной электростанции [4]. Критические звенья сельскохозяйственных цепочек для разных регионов могут отличаться, что обусловлено почвенно-климатическими условиями, спецификой ведения агропромышленного производства и особенностями рационов питания населения. Важность оценки воздействия АЭС на сферу сельскохозяйственного производства для обеспечения радиационной безопасности населения ставит задачу разработки программы, организации и проведения радиационно-экологического мониторинга (РЭМ) агроэкосистем, который должен дать необходимую информацию для анализа последствий влияния работы атомных электростанций на человека и окружающую среду.

На Российских АЭС в настоящее время эксплуатируются несколько типов реакторов (РБМК, ВВЭР, БН, ЭГП) разной мощности. В выполненных ранее исследованиях на основе результатов многолетних наблюдений даны оценки воздействия нормализованных выбросов атомных станций на агроэкосистемы и накопления радионуклидов в местных пищевых продуктах от работы реакторов ВВЭР (Ростовская АЭС) и РБМК (Курская АЭС) [5, 6]. В настоящей статье представлен анализ радиоэкологической ситуации в сельском хозяйстве района Белоярской АЭС и влияния эксплуатации реакторов на быстрых нейтронах (БН-600 и БН-800) на загрязнение радионуклидами сельскохозяйственной и пищевой продукции местного производства.

Белоярская атомная станция (БАЭС) является единственной в стране АЭС с разными типами энергоблоков. Первые два реактора на тепловых нейтронах (АМБ-100 и АМБ-200), запущенные в 1964 и 1967 гг., остановлены более 30 лет назад и сейчас находятся на стадии вывода из эксплуатации. Реакторы № 3 (БН-600 работает с 1980 г.) и № 4 (БН-800 введен в действие в 2016 г.) на быстрых нейтронах эксплуатируются, вырабатывая ежегодно более 8 млрд кВтч электроэнергии. Энергоблок БН-800 с жидким натрием в качестве теплоносителя является на сегодняшний день крупнейшим в мире реактором на быстрых нейтронах $[7,8]$.
БАЭС расположена в 42 км от г. Екатеринбург и в 3,5 км от г. Заречный на берегу Белоярского водохранилища - водоема-охладителя атомной станции. Радиус санитарно-защитной зоны АЭС составляет 3-5 км в границах промплощадки станции, включая территорию Ольховского болота (5 км от АЭС) и трубопровод хозфекального коллектора. Зона наблюдения атомной станции ограничена радиусом 13 км. К промплощадке БАЭС примыкает территория АО «Институт реакторных материалов» (ИРМ), в котором эксплуатируется реактор бассейного типа ИВВ2М мощностью 15 МВт (запущен в 1966 г.). Поскольку радионуклидный состав выбросов ИРМ аналогичен таковым с БАЭС, то при оценке воздействия на окружающую среду, обусловленного радиоактивными выпадениями, указанные радиационно-опасные объекты обычно рассматриваются вместе [7, 8]. Необходимо отметить, что радиоэкологическая обстановка в регионе БАЭС определяется многофакторным воздействием. Это не только выбросы и сбросы самой атомной станции и ИРМ, но и глобальный радиационный фон, выбросы расположенных на расстоянии 125 км предприятий ФГУП «ПО «Маяк», радиоактивное загрязнение ВУРСа и, в некоторой степени, чернобыльские выпадения $[9,10]$. Поэтому при оценке вклада выбросов БАЭС и ИРМ в общее радиоактивное загрязнение района их размещения, обычно применяется сравнение с региональным фоновым уровнем содержания радионуклидов в компонентах окружающей среды, включая аграрные.

В отличие от районов расположения Ростовской и Курской АЭС [5, 6], где земли сельскохозяйственного назначения занимают 93 и 90 \% территории, соответственно, в зоне наблюдения Белоярской атомной станции площадь агроэкосистем составляет лишь 5,3\% (сельскохозяйственное производство - 4,6 \%, сады и огороды - 0,8 \%) [11]. В 15-30 километровой зоне влияния БАЭС площадь сельскохозяйственных угодий существенно увеличивается, особенно в южном направлении. На этих землях ведут агропромышленное производство 21 предприятие и 114 крестьянских и фермерских хозяйств. Наиболее крупными агропредприятиями региона БАЭС являются: ОАО «Косулинское», Птицефабрика «Свердловская», ОАО «Колос», ООО «Некрасово», ФГУП «УЧХОЗ «Уралец», АО АПК «Белореченский», ПК «Мезенское». Основные виды производимой сельскохозяйственной продукции - зерно, картофель, овощи, молоко, мясо, яйцо. В структуре сельскохозяйственных угодий 30-км зоны влияния БАЭС пашня занимает $87,9 \%$ от общей площади, кормовые угодья (сенокосы и пастбища) составляют 12,1 \%.

Почвенный покров сельскохозяйственных земель района БАЭС определяют дерново-подзолистые почвы с пятнами темно-серых лесных. На западе и юге встречаются черноземы выщелоченные. Гранулометрический состав почв варьирует от супесей до суглинков с преобладанием почв легкого и среднего гранулометрического состава. Пахотные почвы преимущественно слабокислые или близкие к нейтральным. 
Газоаэрозольные выбросы БАЭС и ИРМ через воздушный бассейн поступают на почвеннорастительный покров сельскохозяйственных угодий и на поверхность водоемов, использующихся в том числе для орошения полей и водопоя сельскохозяйственных животных. Таким образом, агроэкосистемы с их большой открытой площадью являются естественными природными планшетами, аккумулирующими долгоживущие радионуклиды выбросов БАЭС и ИРМ. Учитывая важность путей поступления техногенных радионуклидов в организм человека с местными сельскохозяйственными пищевыми продуктами, целью настоящей работы являлась оценка современной радиационной обстановки в районе Белоярской АЭС и АО «Институт реакторных материалов» на основе созданной системы радиационноэкологического мониторинга аграрных экосистем.

\section{Материалы и методика исследования}

В соответствии с рекомендациями МАГАТЭ [12] требованиями МУ-13.5.13-00 [13] и разработанным методологическим подходом [4] в 2013 г. в районе размещения БАЭС создана сеть РЭМ агроэкосистем. На
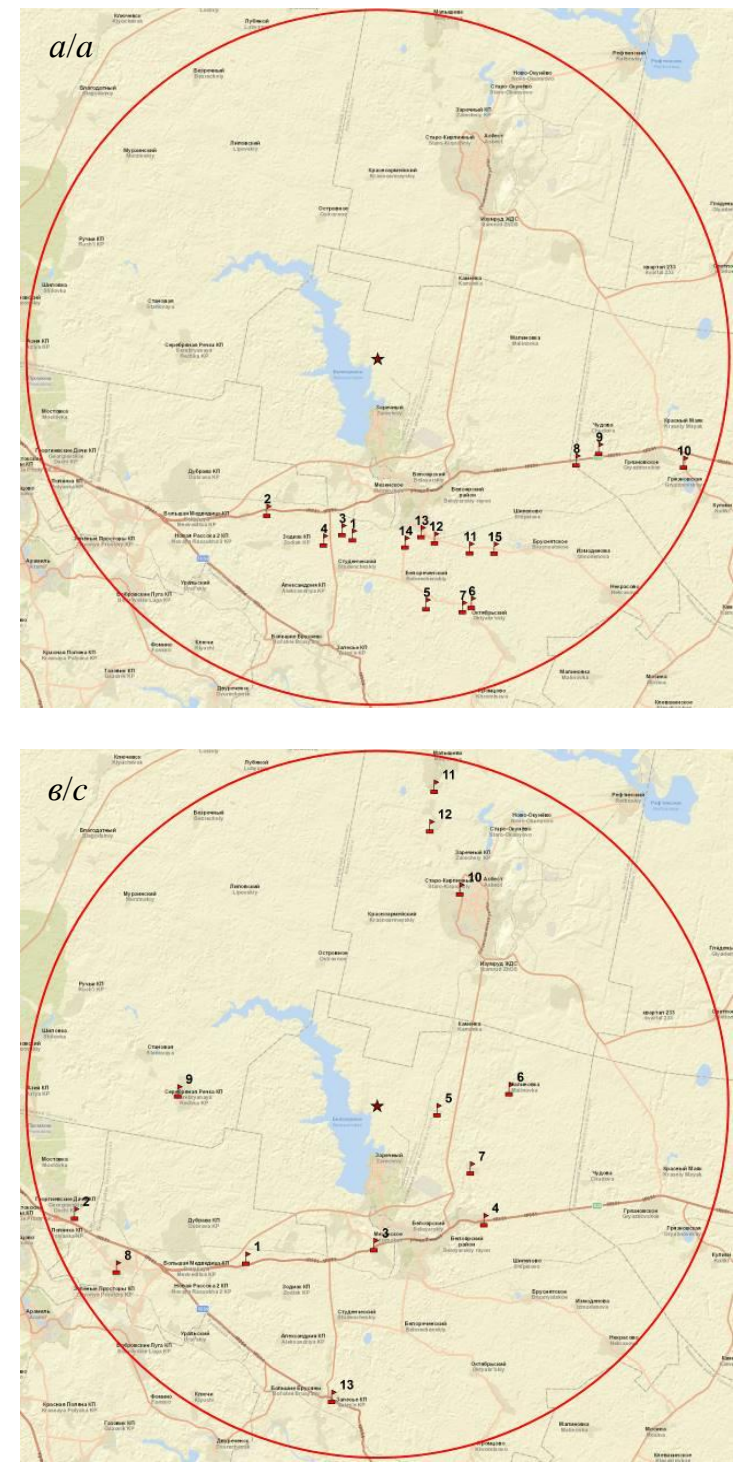

различном расстоянии и направлениях от атомной электростанции заложены контрольные участки - 15 на пашне, 13 на лугопастбищных угодьях и 13 на огородах населенных пунктов. Контрольные участки выбирались с учетом «розы ветров» в период вегетации растений и выпаса животных так, чтобы на доминирующих типах почв региона велось возделывание основных сельскохозяйственных культур, обеспечивая таким образом оценку максимально возможного воздействия БАЭС и ИРМ на агроэкосистемы. Количество контрольных участков, их размещение и число отбираемых проб являлось достаточным для пространственной характеризации уровней содержания радионуклидов в почве агроэкосистем и сельскохозяйственной продукции. Пашня в 30-км зоне влияния атомной электростанции преимущественно расположена в южном и юго-восточных направлениях на расстоянии 15-30 км от станции; лугопастбищные угодья - во всех направлениях, кроме северного, на расстоянии 10-30 км от БАЭС; огороды на территории населенных пунктов выбраны равномерно в разных направлениях от АЭС на расстоянии от 5 до 30 км (рис. 1).

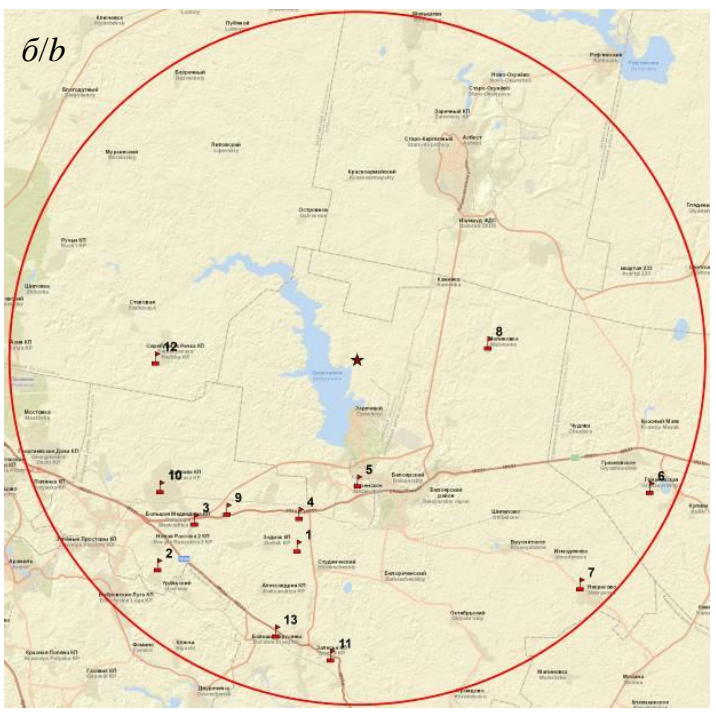

Pис. 1. Карты-схемы размещения контрольных участков сети РЭМ в 30-км зоне влияния Белоярской АЭС: а) на пашне, б) на лугопастбищных угодьях, в) на огородах населенных пунктов ( ка БАЭС; иифры - номера контрольных участков)

Fig. 1. Schematic maps of control sites of the radioecological monitoring network in the 30- $\mathrm{km}$ zone of Beloyarsk NPP: a) arable land, b) grassland, c) vegetable garden of settlements ( - Beloyarsk NPP; digit - number of control sites) 
Мониторинговые исследования проводились в одно и то же время (август) в 2013 г. на этапе завершения строительства энергоблока БН-800 и в 2019 г., через три года после начала его промышленной эксплуатации. Это дало возможность оценить как многолетнее влияние работы реактора БН-600 на агроэкосистемы, так и изменение радиоэкологической ситуации после начала функционирования нового энергоблока БН-800.

На контрольных участках измеряли мощность амбиентного эквивалента дозы (МАЭД), отбирали пробы почв (на пашне пахотный горизонт глубиной 0-20 cм, на лугах и пастбищах верхний слой почвы глубиной 0-10 см), продукции растениеводства, кормопроизводства и животноводства. На пастбищных участках № 10 и № 12 брались пробы почвы послойно, что позволило оценить динамику вертикального распределения радионуклидов в почвенном профиле. Продукция растениеводства отбиралась сопряженно с почвой и далее разделялась на хозяйственно-ценную (зерно, клубне- и корнеплоды, овощи) и побочную часть (солома и др.). На участках, где велось наблюдение за миграцией радионуклидов по животноводческой цепочке, проводился отбор проб почвы, рациона сельскохозяйственных животных, молока и говядины. Всего исследовано в 2013 г. - 137, в 2019 г. - 94 образца. В компонентах агроэкосистем оценивали содержание ${ }^{40} \mathrm{~K},{ }^{226} \mathrm{Ra},{ }^{232} \mathrm{Th}$, ${ }^{54} \mathrm{Mn},{ }^{59} \mathrm{Fe},{ }^{60} \mathrm{Co},{ }^{90} \mathrm{Sr},{ }^{131} \mathrm{I},{ }^{134} \mathrm{Cs}{ }^{137} \mathrm{Cs},{ }^{239,240} \mathrm{Pu}$. В сотрудничестве со специалистами АО «Радиевый институт имени В.Г. Хлопина» в ряде проб сельскохозяйственной продукции определяли ${ }^{3} \mathrm{H}$ и ${ }^{14} \mathrm{C}$. Пробоподготовку и измерения проб проводили в лаборатории радиационного контроля ФГБНУ ВНИИРАЭ (аттестат аккредитации RA.RU.21АД81). Для анализа содержания радионуклидов использовали высокочувствительные радиометрические и спектрометрические комплексы. Гамма-излучающие радионуклиды определяли на спектрометре ГАММА-1П с двумя измерительными трактами с полупроводниковыми детекторами из особо чистого германия («ЛСРМ», Россия, «EG\&G ORTEC», США) и многоканальном гамма-спектрометре CANBERRA («Canberra Industries, Inc.», США). ${ }^{90} \mathrm{Sr}$ из проб выделяли радиохимическим способом. Альфа- и бета-активность препаратов измеряли на жидкосцинтилляционном спектрометре TRI-CARB 4810 TR («Perkin Elmer», США), жидкосцинтилляционном спектрометрическом комплексе СКС-07П-Б11 («Green Star», Россия) и альфа-бета радиометре с кремниевым детектором УМФ-2000 (НПП «Доза», Россия). Относительная погрешность измерений активности радионуклидов составляла 6-30\% в зависимости от типа прибора и метода измерения [14]. Используемые средства измерений и методическое обеспечение, обеспечивали достоверное определение содержания радионуклидов в почве и сельскохозяйственной продукции на уровне значений регионального фона. Полученные данные по содержанию радионуклидов в продукции растениеводства и животноводства на их соответствие радиологическим стандартам сравнивали с нормативами $[15,16]$, продукции кормопроизводства c [17].

\section{Результаты исследования и обсуждение}

Основной целью РЭМ является обеспечение радиационной безопасности населения и выявление тенденций изменения радиоэкологической обстановки в регионе размещения АЭС в процессе ее эксплуатации. Поэтому на первом этапе анализа результатов мониторинга оценили плотность загрязнения контрольных участков ${ }^{137} \mathrm{Cs}$ - основным радиологически значимым долгоживущим радионуклидом (рис. 2).
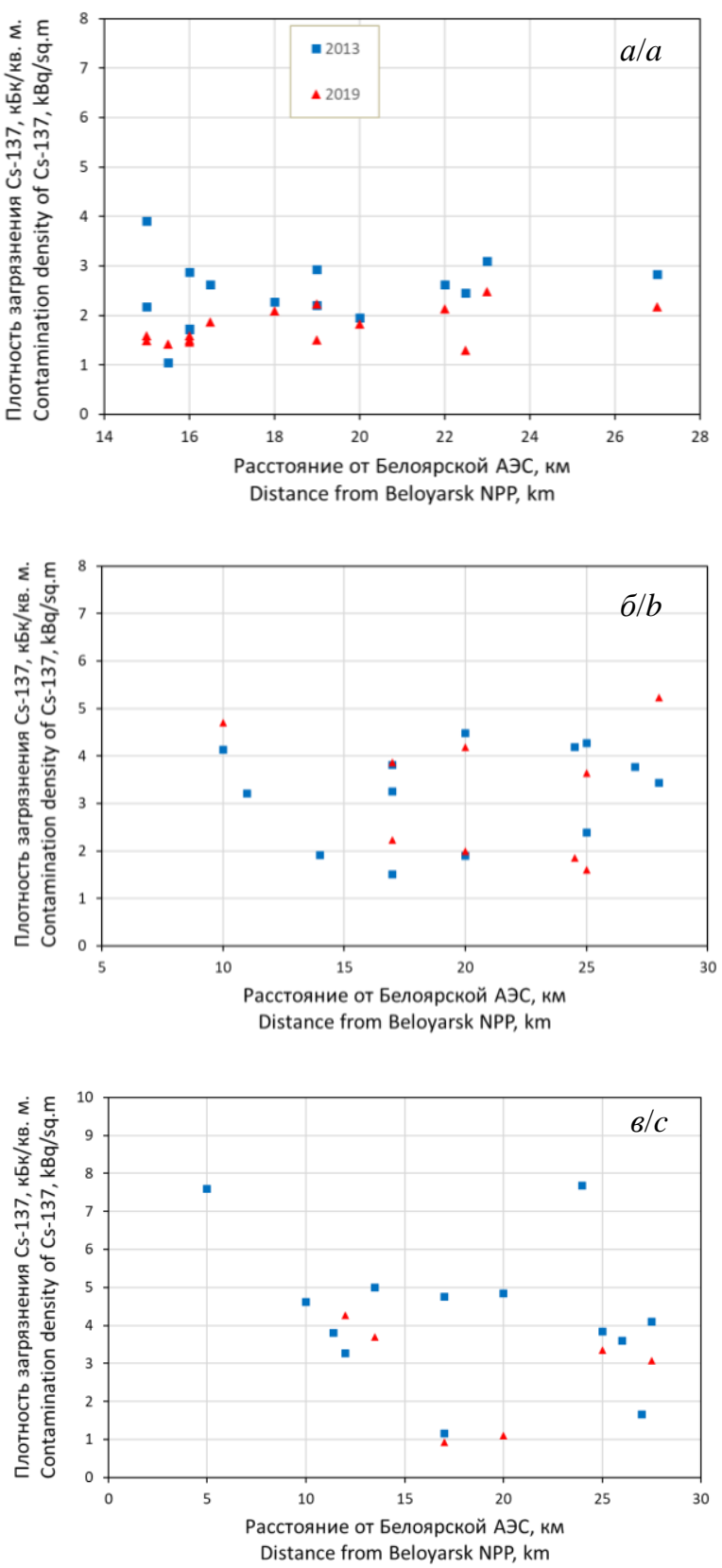

Puc. 2. Плотность загрязнения ${ }^{137}$ Cs почв сельскохозяйственный угодий: а) пашни, б) лугопастбищных угодий, в) огородов в районе Белоярской АЭС в 2013 и 2019 г2. на различном расстоянии от атомной станиии

Fig. 2. ${ }^{137}$ Cs contamination density of agricultural lands: a) arable, b) grassland, c) vegetable garden in the vicinity of Beloyarsk NPP in 2013 and 2019 at different distance from the nuclear power plant 
Уровни загрязнения ${ }^{137} \mathrm{Cs}$ почв пашни в $30-$ км зоне влияния БАЭС варьировали в пределах: 1,1 ...3,9 кБк/м² в 2013 г. и 1,3...2,5 кБк/м² в 2019 г. Диапазон данных по плотностям загрязнения ${ }^{137} \mathrm{Cs}$ лугопастбищных угодий оказался несколько шире: $1,5 \ldots 4,5$ кБк/ ${ }^{2}$ в 2013 г. и 1,6...5,2 кБк/м² в 2019 г. Плотности загрязнения ${ }^{137} \mathrm{Cs}$ почв огородов находились в пределах $0,9 \ldots 5,0$ кБк/м² за исключением двух населенных

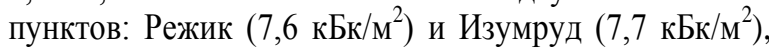
расположенных в 5 и 24 км от БАЭС, соответственно. За время более чем 50-летней работы атомной станции следствием несовершенства на ранних этапах ее эксплуатации технологий очистки выбросов стало образование локальных участков с повышенным уровнем содержания радионуклидов в почвенном покрове с подветренной стороны БАЭС. В то же время эти два контрольных участка нельзя отнести к радиоактивно загрязненным, поскольку плотность их загрязнения ${ }^{137} \mathrm{Cs}$ не подпадает под границы зонирования

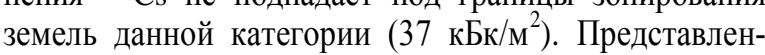
ные результаты служат примером радиоэкологической ситуации в районе не только действующих объектов, но и мест радиационного наследия, характерных для такого рода предприятий ядерно-топливного цикла. Из рис. 2 также видно, что показатели плотностей загрязнения сельхозугодий ${ }^{137} \mathrm{Cs}$ находились примерно на одном уровне вне зависимости от расстояния от БАЭС и года отбора проб, т. е. начало эксплуатации реактора БН-800 не привело к регистрируемому увеличению поступления ${ }^{137} \mathrm{Cs}$ в окружающую среду, включая агроэкосистемы. В целом можно отметить, что газоаэрозольные выбросы БАЭС и ИРМ не вносят значимого вклада в уровни техногенного загрязнения сельскохозяйственных угодий зоны влияния атомной электростанции. По данным других исследований, деятельность Уральских предприятий ЯТЦ увеличивает плотность загрязнения почв регио-

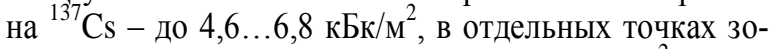
ны наблюдения БАЭС она достигает 9,0 кБк/м ${ }^{2}$ [18].

По результатам мониторинга среднее содержание ${ }^{90} \mathrm{Sr}$ в почве агроэкосистем района размещения БАЭС и ИРМ составляет 4,3...7,2 Бк/кг, ${ }^{137} \mathrm{Cs}$ варьирует в пределах 7,5...18,9 Бк/кг. Вариации уровней загрязнения ${ }^{137} \mathrm{Cs}$ почв наиболее крупных хозяйств 30-км зоны атомной станции незначительны: для ФГУП «УЧХОЗ «Уралец» они составляют 4...16 Бк/кг, для АО АПК «Белореченский» - 10...12 Бк/кг. Диапазон вариации среднего содержания в почве рассматриваемого региона естественных радионуклидов составляет: для ${ }^{40} \mathrm{~K}$ $286 \ldots 432$ Бк/кг, для ${ }^{226} \mathrm{Ra} 16,1 \ldots 21,7$ Бк/кг, для ${ }^{232} \mathrm{Th}$ $20,1 \ldots 25,5$ Бк/кг (табл. 1). В 10 пробах почв агроэкосистем измерен ${ }^{239,240} \mathrm{Pu}$, среднее содержание которого составило 0,13 Бк/кг при вариации 0,07...0,25 Бк/кг. Поскольку уровень удельной активности изотопов плутония в почве низок и находится в пределах регионального фона, достаточно сложно определить источник его происхождения: выбросы БАЭС и ИРМ, предприятий ФГУП «ПО «Маяк» или глобальные выпадения от испытаний ядерного оружия. Полученные результаты по содержанию радионуклидов в почве хорошо согласуются как с данными из международных источников [19], так и с результатами исследований, проведенных в регионах размещения других Российских АЭС $[5,6]$.

Таблица 1. Содержание естественных и техногенных радионуклидов в почве сельскохозяйственных угодий в районе размещения Белоярской АЭС, Бк/кг

Table 1. Content of natural and artificial radionuclides in soil of agricultural lands in the vicinity of the Beloyarsk NPP, $B q / \mathrm{kg}$

\begin{tabular}{|c|c|c|c|c|c|c|c|}
\hline $\begin{array}{l}\text { Год } \\
\text { Year }\end{array}$ & $\begin{array}{c}\text { Число проб } \\
\text { Number of } \\
\text { samples }\end{array}$ & $\begin{array}{c}\text { МАЭД, мкЗв/ч } \\
\text { Ambient dose equivalent } \\
\text { rate, } \mu \mathrm{Sv} / \mathrm{h}\end{array}$ & ${ }^{40} \mathrm{~K}$ & ${ }^{226} \mathrm{Ra}$ & ${ }^{232} \mathrm{Th}$ & ${ }^{90} \mathrm{Sr}$ & ${ }^{137} \mathrm{Cs}$ \\
\hline \multicolumn{8}{|c|}{ Пашня/Arable land } \\
\hline \multirow{2}{*}{2013} & \multirow{2}{*}{15} & $0,11^{*}$ & 299 & 16,6 & 24,1 & 5,0 & 10,1 \\
\hline & & $0,10 \ldots 0,12$ & $194 \ldots 440$ & $6,8 \ldots 26,2$ & $12,8 \ldots 32,7$ & $2,4 \ldots 8,1$ & $4,4 \ldots 16,3$ \\
\hline \multirow{2}{*}{2019} & \multirow{2}{*}{14} & 0,11 & 400 & 19,0 & 25,5 & 4,3 & 7,5 \\
\hline & & $0,08 \ldots 0,13$ & $248 \ldots 463$ & $14,3 \ldots 28,8$ & $13,1 \ldots 30,9$ & $1,4 \ldots 8,5$ & $5,4 \ldots 10,0$ \\
\hline \multicolumn{8}{|c|}{ Луга и пастбища/Meadows and pastures } \\
\hline \multirow{2}{*}{2013} & \multirow{2}{*}{13} & 0,10 & 286 & 16,1 & 20,1 & 5,6 & 13,5 \\
\hline & & $0,08 \ldots 0,13$ & $225 \ldots 389$ & $6,2 \ldots 29,4$ & $8,4 \ldots 37,3$ & $1,0 \ldots 11,4$ & $6,3 \ldots 18,3$ \\
\hline \multirow{2}{*}{2019} & \multirow{2}{*}{9} & 0,10 & 377 & 21,7 & 24,6 & 4,6 & 13,1 \\
\hline & & $0,09 \ldots 0,10$ & $265 \ldots 450$ & $13,5 \ldots 34,0$ & $13,9 \ldots 30,0$ & $1,6 \ldots 7,3$ & $6,7 \ldots 21,8$ \\
\hline \multicolumn{8}{|c|}{ Огороды/Vegetable gardens } \\
\hline \multirow{2}{*}{2013} & \multirow{4}{*}{13} & 0,09 & 357 & 16,1 & 21,1 & 6,0 & 18,9 \\
\hline & & $0,08 \ldots 0,10$ & $186 \ldots 567$ & $6,4 \ldots 31,7$ & $7,9 \ldots 36,6$ & $2,5 \ldots 11,6$ & $8,8 \ldots 32,1$ \\
\hline \multirow{2}{*}{2019} & & 0,11 & 432 & 21,3 & 20,8 & 7,2 & 11,9 \\
\hline & & $0,09 \ldots 0,12$ & $306 \ldots 640$ & $17,3 \ldots 28,2$ & $15,8 \ldots 32,6$ & $1,3 \ldots 12,9$ & $4,3 \ldots 17,8$ \\
\hline \multicolumn{8}{|c|}{ Другие регионы России/Other regions of Russian Federation } \\
\hline \multirow{2}{*}{\multicolumn{2}{|c|}{$\begin{array}{l}\text { Среднее в РФ } \\
\text { Average in Russia [19] }\end{array}$}} & 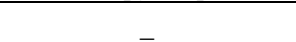 & 520 & 27,0 & 30,0 & - & - \\
\hline & & 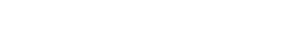 & $100 \ldots 1400$ & $1,0 \ldots 76,0$ & $2,0 \ldots 79,0$ & & - \\
\hline \multirow{2}{*}{\multicolumn{2}{|c|}{$\begin{array}{l}\text { По данным } \\
\text { According to [5] }\end{array}$}} & 0,13 & 589 & 25,1 & 34,6 & 4,0 & 10,2 \\
\hline & & $0,11 \ldots 0,13$ & $561 \ldots 634$ & $23,4 \ldots 27,5$ & $32,7 \ldots 35,9$ & $1,7 \ldots 7,4$ & $7,5 \ldots 14,9$ \\
\hline \multicolumn{2}{|c|}{ По данным } & 0,13 & 572 & 25,5 & 35,5 & 3,6 & 27,4 \\
\hline \multicolumn{2}{|c|}{ According to [6] } & $0,11 \ldots 0,15$ & $481 \ldots 625$ & $20,6 \ldots 29,5$ & $28,2 \ldots 39,2$ & $2,7 \ldots 4,5$ & $14,6 \ldots 40,8$ \\
\hline
\end{tabular}

* Числитель - среднее, знаменатель-мин.-макс./Numerator-average, denominator-min.-max 
Оценка МАЭД проводилась с целью выявления возможных мест локальных радиоактивных загрязнений и участков с повышенным гамма фоном. МАЭД на контрольных участках находилась в диапазоне $0,08 \ldots 0,13$ мкЗв/ч, при среднем 0,10 мкЗв/ч. Поскольку значимой разницы в МАЭД между пахотными угодьями и лугопастбищными участками обнаружено не было, можно говорить, что большая часть целинных сельскохозяйственных угодий ранее были нарушены многократной агротехнической обработкой. Анализ результатов измерения МАЭД также не выявил достоверных отличий в величине мощности дозы во времени и на различном расстоянии от БАЭС и ИРМ. Диапазон данных МАЭД соответствовал региональному фону с учетом свойств почв и вида агроэкосистем.

На примере двух пастбищных участков № 10 и 12 дана оценка распределения ${ }^{137} \mathrm{Cs}$ в почвенном профиле на глубину до 20 см и динамики вертикальной ми- грации данного радионуклида (рис. 3). Отмечен различный характер нахождения ${ }^{137} \mathrm{Cs}$ в почве. Так, на участке № 10 от 60 до $80 \%$ запаса радиоцезия аккумулировано в верхнем пятисантиметровом слое почвы, что говорит об отсутствии влияния на почву пастбища антропогенной деятельности. На участке № 12 радионуклиды ${ }^{137} \mathrm{Cs}$ распределены достаточно равномерно (по 15-30 \% в каждом слое), и, следовательно, участок ранее перепахивался. За семилетний период на обоих участках произошло некоторое перераспределение радионуклидов в более глубокие слои почв, что обусловлено как отсутствием значимого внешнего поступления ${ }^{137} \mathrm{Cs}$, так и определенными миграционными процессами распределения радионуклидов в почвенном профиле. Таким образом, за время наблюдений выбросы БАЭС и ИРМ не оказали влияния на увеличение содержания ${ }^{137} \mathrm{Cs}$ в почвах агроэкосистем, прилегающих к атомной электростанции.
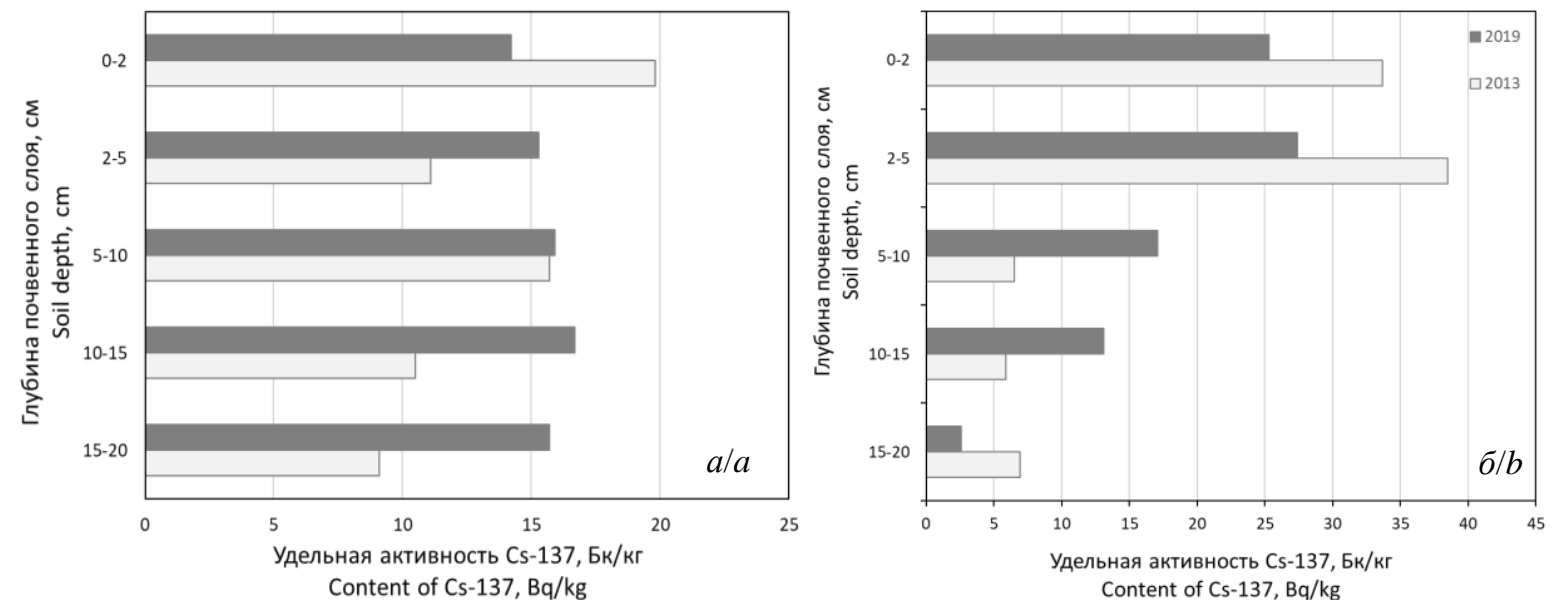

Рис. 3. Распределение ${ }^{137}$ Cs в почвенном профиле контрольных участков лугопастбищных угодий: а) № 10; б) № 12 в районе Белоярской АЭС в 2013 и 2019 г2.

Fig. 3. ${ }^{137} \mathrm{Cs}$ distribution in the soil profile of grassland control plots: a) no. 10; b) no. 12 in the vicinity of Beloyarsk NPP in 2013 and 2019

Содержание природного ${ }^{40} \mathrm{~K}$ в продукции растениеводства района Белоярской АЭС варьировало в достаточно широких пределах - от 48 до 526 Бк/кг, что определяется видовыми особенностями растений и характеристиками почв, где выращиваются культуры (табл. 2). В продукции кормопроизводства накопление ${ }^{40} \mathrm{~K}$ отмечено в диапазоне $260 \ldots 543$ Бк/кг, в животноводческой продукции в более узких пределах 18...97 Бк/кг. Данные результаты являются средними показателями, характерными для сельскохозяйственной пищевой продукции Уральского региона.

С точки зрения радиационной безопасности населения, проживающего в районе БАЭС и ИРМ, важным является анализ содержания техногенных радионуклидов в производимой сельскохозяйственной и пищевой продукции, а также оценка ее соответствия установленным радиологическим стандартам. За весь период мониторинговых наблюдений ни в одной из проб агропродукции не обнаружено превышения нормативов [15-17] по содержанию ${ }^{90} \mathrm{Sr}$ и ${ }^{137} \mathrm{Cs}$ (табл. 2). Так, удельная активность радионуклидов в продовольственном зерне наблюдалась в диапазонах: для ${ }^{90} \mathrm{Sr} 1,03 \ldots 2,8$ Бк/кг, для ${ }^{137} \mathrm{Cs} 0,15 \ldots 0,94$ Бк/кг. Максимальные уровни накопления ${ }^{137} \mathrm{Cs}$ зафиксированы в ячмене, но они оказались ниже норматива СанПиН в 64 раза. Необходимо отметить, что ни на одном контрольном участке не выделены тренды на увеличение содержания ${ }^{90} \mathrm{Sr}$ и ${ }^{137} \mathrm{Cs}$ в зерновых. Вариации данных по удельной активности радионуклидов в данном виде сельскохозяйственной продукции объясняются гранулометрическим составом почв пашни, сортовыми особенностями растений, погодными условиями и дозами вносимых минеральных удобрений, что в совокупности влияет на степень накопления радионуклидов в растениях. Так, отличия в концентрации ${ }^{40} \mathrm{~K}$ в зерне для одной и той же культуры в разные годы составили 1,9...2,7 раза, для техногенных радионуклидов 1,2...3,9 раза.

При мониторинге радиационной обстановки следует обращать особое внимание на продукты питания 
местного производства с минимальной технологической кулинарной переработкой. Результаты оценки содержания радионуклидов в овощах, картофеле и бахчевых района БАЭС и ИРМ показали, что максимальные уровни удельной активности как ${ }^{90} \mathrm{Sr}$ $\left(0,84\right.$ Бк/кг), так и ${ }^{137} \mathrm{Cs}(0,26$ Бк/кг) отмечались в свекле в 2013 г., однако и они оказались ниже нормативов СанПиН в 45 и 300 раз, соответственно. Из данных табл. 2 также видно, что при достаточно большом наборе анализируемой продукции растение- водства, производящейся в районе влияния атомной электростанции, нельзя выделить какие-либо продукты с повышенными уровнями накопления радионуклидов или имеющими тенденцию к такому увеличению. Таким образом, эксплуатация нового энергоблока БН-800 не привела к повышению содержания техногенных радионуклидов в продукции растениеводства, а в некоторых из них (например, в свекле и тыкве) отмечено снижение концентрации ${ }^{90} \mathrm{Sr}$ и ${ }^{137} \mathrm{Cs}$ в течение 7 лет.

Таблица 2. Содержание радионуклидов в сельскохозяйственной продукиии, произведенной в районе Белоярской АЭС в 2013 и 2019 г2., Бк/кг(л)

Table 2. Content of radionuclides in agricultural products produced in the vicinity of the Beloyarsk NPP in 2013 and 2019, $B q / k g(L)$

\begin{tabular}{|c|c|c|c|c|c|c|}
\hline \multirow{2}{*}{$\begin{array}{c}\text { Сельскохозяйственная продукция } \\
\text { Agricultural products }\end{array}$} & \multirow{2}{*}{$\begin{array}{c}\text { Число проб } \\
\text { Number of samples }\end{array}$} & \multirow[t]{2}{*}{${ }^{40} \mathrm{~K}$} & \multirow[t]{2}{*}{${ }^{90} \mathrm{Sr}$} & \multirow[t]{2}{*}{${ }^{137} \mathrm{Cs}$} & \multicolumn{2}{|c|}{$\begin{array}{c}\text { Допустимые уровни } \\
\text { Permissible levels }\end{array}$} \\
\hline & & & & & ${ }^{90} \mathrm{Sr}$ & ${ }^{137} \mathrm{Cs}$ \\
\hline \multicolumn{7}{|c|}{ Продукция растениеводства/Crop products } \\
\hline \multirow{2}{*}{ Ячмень, зерно/Grain of barley } & $4 *$ & $146 \pm 12$ & $1,35 \pm 0,11$ & $0,94 \pm 0,48$ & \multirow{8}{*}{-} & \multirow{8}{*}{60} \\
\hline & $3 * *$ & $395 \pm 244$ & $1,03 \pm 0,57$ & $0,24 \pm 0,15$ & & \\
\hline \multirow{2}{*}{$\begin{array}{l}\text { Озимая пшеница, зерно } \\
\text { Grain of winter wheat }\end{array}$} & 4 & $159 \pm 24$ & $2,37 \pm 1,58$ & $0,36 \pm 0,23$ & & \\
\hline & 3 & $373 \pm 174$ & $2,8 \pm 1,44$ & $0,54 \pm 0,39$ & & \\
\hline \multirow{2}{*}{ Овес, зерно/Grain of oat } & 1 & $178 \pm 33$ & $1,57 \pm 0,22$ & $0,84 \pm 0,41$ & & \\
\hline & 1 & $334 \pm 269$ & $2,16 \pm 1,21$ & $0,26 \pm 0,22$ & & \\
\hline \multirow{2}{*}{ Тритикале, зерно/Grain of triticale } & 1 & $86 \pm 19$ & $2,18 \pm 0,31$ & $0,39 \pm 0,20$ & & \\
\hline & 1 & $164 \pm 13$ & $2,8 \pm 1,1$ & $0,15 \pm 0,05$ & & \\
\hline \multirow{2}{*}{ Горох/Peas } & 1 & $466 \pm 19$ & $0,8 \pm 0,11$ & $0,83 \pm 0,70$ & \multirow{2}{*}{-} & \multirow{2}{*}{-} \\
\hline & 1 & $526 \pm 44$ & $1,05 \pm 0,31$ & $0,32 \pm 0,1$ & & \\
\hline \multirow{2}{*}{ Кабачки/Zucchini } & 7 & $56 \pm 9$ & $0,15 \pm 0,07$ & $0,05 \pm 0,04$ & \multirow{16}{*}{40} & \multirow{16}{*}{80} \\
\hline & 5 & $78 \pm 14$ & $0,05 \pm 0,02$ & $0,04 \pm 0,03$ & & \\
\hline \multirow{2}{*}{ Капуста/Cabbage } & 4 & $56 \pm 11$ & $0,4 \pm 0,03$ & $0,04 \pm 0,03$ & & \\
\hline & 1 & $72 \pm 6$ & $0,6 \pm 0,02$ & $\overline{0,012 \pm 0,006}$ & & \\
\hline \multirow{2}{*}{ Картофель/Potato } & 10 & $139 \pm 58$ & $0,22 \pm 0,14$ & $0,06 \pm 0,03$ & & \\
\hline & 6 & $157 \pm 60$ & $0,21 \pm 0,09$ & $0,05 \pm 0,04$ & & \\
\hline \multirow{2}{*}{ Морковь/Carrot } & 6 & $129 \pm 18$ & $0,16 \pm 0,01$ & $0,05 \pm 0,02$ & & \\
\hline & 3 & $125 \pm 81$ & $0,23 \pm 0,15$ & $0,06 \pm 0,01$ & & \\
\hline \multirow{2}{*}{ Огурцы/Cucumber } & 5 & $48 \pm 12$ & $0,04 \pm 0,02$ & $0,08 \pm 0,06$ & & \\
\hline & 2 & $72 \pm 2$ & $0,03 \pm 0,01$ & $0,01 \pm 0,001$ & & \\
\hline \multirow{2}{*}{ Свекла/Beetroot } & 3 & $128 \pm 28$ & $0,84 \pm 0,08$ & $0,26 \pm 0,22$ & & \\
\hline & 1 & $96 \pm 10$ & $0,1 \pm 0,03$ & $0,07 \pm 0,02$ & & \\
\hline Томаты/Tomato & 2 & $113 \pm 27$ & $0,08 \pm 0,06$ & $0,13 \pm 0,05$ & & \\
\hline Томаты/Tomato & 2 & $70 \pm 1$ & $0,18 \pm 0,03$ & $0,05 \pm 0,03$ & & \\
\hline Turono/Pumplin & 2 & $91 \pm 1$ & $0,17 \pm 0,02$ & $0,03 \pm 0,01$ & & \\
\hline Іыква/Pumpkin & 1 & $62 \pm 5$ & $0,08 \pm 0,02$ & $0,01 \pm 0,006$ & & \\
\hline & родукция кормопроя & водства/Fee & production & & & \\
\hline 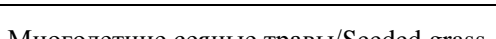 & 8 & $330 \pm 115$ & $1,78 \pm 1,66$ & $1,33 \pm 0,70$ & & \\
\hline Многолетние сеяные травы/seeded grass & 6 & $543 \pm 126$ & $1,24 \pm 0,66$ & $0,52 \pm 0,36$ & & \\
\hline & 5 & $383 \pm 106$ & $3,5 \pm 0,5$ & $1,76 \pm 0,73$ & 50 & 100 \\
\hline Естественные травы/Natural grass & 3 & $441 \pm 78$ & $2,97 \pm 1,88$ & $0,72 \pm 0,32$ & & \\
\hline Сопоме ?enuruy/Stray & 11 & $303 \pm 79$ & $2,34 \pm 1,42$ & $2,05 \pm 1,99$ & 180 & 400 \\
\hline Солома зерновых/Straw & 5 & $521 \pm 278$ & $3,60 \pm 1,09$ & $0,7 \pm 0,5$ & 180 & 400 \\
\hline Комбикорм/Animal feeds & $4 * *$ & $260 \pm 76^{* *}$ & $1,59 \pm 1,08 * *$ & $0,15 \pm 0,06^{* *}$ & 140 & 200 \\
\hline Продукция & отноводства и птиц & одства/Live & ock and poult & products & & \\
\hline Monoro Mill & 10 & $57 \pm 14$ & $0,18 \pm 0,14$ & $0,11 \pm 0,09$ & 25 & 100 \\
\hline Молоко/Milk & 7 & $39 \pm 4$ & $0,41 \pm 0,21$ & $0,04 \pm 0,02$ & 25 & 100 \\
\hline Говядина/Beef & $1 * *$ & $35 \pm 3 * *$ & $2,4 \pm 0,1 * *$ & $0,12 \pm 0,03 * *$ & & 200 \\
\hline Свинина/Pork & $1 *$ & $97 \pm 10 *$ & $0,18 \pm 0,1^{*}$ & $0,26 \pm 0,2 *$ & & \\
\hline & 1 & $56 \pm 3$ & $0,29 \pm 0,02$ & $0,13 \pm 0,1$ & - & - \\
\hline Мясо кур/Chicken meat & 1 & $18 \pm 2$ & $0,2 \pm 0,1$ & $0,16 \pm 0,1$ & & \\
\hline
\end{tabular}

$*-2013, * *-2019$.

Естественные и сеяные травы, а также солома зерновых, использующиеся для корма сельскохозяйственных животных, накапливают радионуклиды в большей степени по сравнению с зерном, что связано с биоло- гическими особенностями растений. В соломе зерновых с контрольных участков района БАЭС среднее содержание ${ }^{90} \mathrm{Sr}$ варьировало в пределах 2,3...3,6 Бк/кг, ${ }^{137} \mathrm{Cs} 0,7 \ldots 2,1$ Бк/кг. В травостое этот диапазон состав- 
лял $1,2 \ldots 3,5$ Бк/кг для ${ }^{90} \mathrm{Sr}$ и $0,5 \ldots 1,8$ Бк/кг для ${ }^{137} \mathrm{Cs}$, соответственно. Максимальные уровни удельной активности ${ }^{90} \mathrm{Sr}$ в соломе в период наблюдений оказались в 50 раз ниже норматива по содержанию этого радионуклида в кормах [17], по ${ }^{137} \mathrm{Cs}$ эта разница составила 190 раз. Максимальные уровни содержания ${ }^{90} \mathrm{Sr}$ в траве оказались в 14 раз ниже норматива, по ${ }^{137} \mathrm{Cs}$ почти в 56 раз. В целом представленные результаты показывают, что продукция растениеводства, производящаяся в районе БАЭС и ИРМ, соответствует радиологическим стандартам с большими коэффициентами запаса и не оказывает влияния на формирование дополнительной дозовой нагрузки на население региона атомной электростанции.

Данные мониторинга за 7 лет демонстрируют, что динамика содержания техногенных радионуклидов в молоке зоны влияния БАЭС и ИРМ разнонаправлена: по ${ }^{90} \mathrm{Sr}$ оно несколько возросло, по ${ }^{137} \mathrm{Cs}$ уменьшилось Однако даже максимальные значения удельной активности ${ }^{90} \mathrm{Sr}\left(0,41\right.$ Бк/л) и ${ }^{137} \mathrm{Cs}(0,11$ Бк/л) в молоке оказались ниже граничных уровней, установленных действующими нормативами СанПиН в 60 раз по радиостронцию и в 900 раз по радиоцезию. Многолетняя эксплуатация БАЭС и ИРМ, а также запуск нового энергоблока БН-800 не привели к регистрируемому увеличению содержания техногенных радионуклидов и в мясной продукции (говядине и свинине) а также птице. В мясе кур концентрация ${ }^{90} \mathrm{Sr}$ и ${ }^{137} \mathrm{Cs}$ в последние годы остается на стабильно низком уровне, а нормируемое содержание ${ }^{137} \mathrm{Cs}$ в говядине в 2019 г. оказалось более чем в 1,5 тыс. раз ниже требований СанПиН (табл. 2). Таким образом, можно заключить, что содержание ${ }^{90} \mathrm{Sr}$ и ${ }^{137} \mathrm{Cs}$ в продукции животноводства, производящейся в зоне влияния БАЭС и ИРМ, в последние годы находится на очень низком уровне, а начало эксплуатации реактора БН-800 не привело к повышению в ней содержания основных дозообразующих техногенных радионуклидов.

По данным мониторинговых исследований 2013 и 2019 гг., сельскохозяйственную и пищевую продукцию, производимую в районе БАЭС и ИРМ, по накоплению ${ }^{90} \mathrm{Sr}$ можно расположить в следующий ряд: солома $(2,7$ Бк/кг) $\geq$ травы $(2,6$ Бк/кг) $>$ зерно $(2,0$ Бк/кг) > мясо $(0,8$ Бк/кг) > молоко $(0,3$ Бк/л) $\geq$ корнеплоды $(0,29$ Бк/кг) > овощи $(0,18$ Бк/кг). По среднему содержанию ${ }^{137} \mathrm{Cs}$ ряд сельскохозяйственных и пищевых продуктов будет выглядеть аналогично: солома $(1,2$ Бк/кг) $\geq$ травы $(1,1$ Бк/кг) > зерно $(0,5$ Бк/кг) > мясо $(0,2$ Бк/кг) > молоко $(0,08$ Бк/л) $\geq$ корнеплоды $(0,08$ Бк/кг) > овощи $(0,05$ Бк/кг). Как видно из представленных последовательностей, во всех видах сельскохозяйственной продукции уровень накопления ${ }^{90} \mathrm{Sr}$ в 2,2...4,6 раза выше по сравнению с ${ }^{137} \mathrm{Cs}$, на что в определенной степени, возможно, влияет стронциевое загрязнение от аварийных выпадений на ПО «Маяк» в 1957 г., образовавших Восточно-Уральский радиоактивный след (ВУРС).

При оценке радиационной обстановки в районах размещения АЭС необходимо учитывать не только радионуклиды ${ }^{90} \mathrm{Sr}$ и ${ }^{137} \mathrm{Cs}$, но и такие малоизученные, как ${ }^{3} \mathrm{H},{ }^{14} \mathrm{C}$, ${ }^{129} \mathrm{I}$. В последние годы показан суще- ственный потенциал этих биофильных изотопов, присутствующих в составе выбросов и сбросов атомных электростанций и других объектов ядернотопливного цикла, в формирование дозовых нагрузок на человека и биоту [20-22]. Так, по оценкам НКДАР $\mathrm{OOH}{ }^{3} \mathrm{H}$ и ${ }^{14} \mathrm{C}$ вносят от 81 до $92 \%$ в дозу облучения населения от реакторов PWR, BWR, FBR [23]. Тритий и углерод-14 активно мигрируют в природных средах и способны проникать в ткани и генные структуры живых организмов, вызывая мутагенные и соматические нарушения. В отличие от других радионуклидов они плохо удерживаются очистными барьерами, слабо сорбируются грунтами и поэтому в природных условиях переносятся на большие расстояния. Тритий, находясь в водяном паре, включается в формирование осадков, тем самым поступая в продукты питания и питьевую воду, которые потребляются населением. Оценка роли ${ }^{3} \mathrm{H}$ и ${ }^{14} \mathrm{C}$ в формировании дозовых нагрузок на население от выбросов АЭС является сложной методической задачей, поскольку в настоящее время отсутствуют верифицированные модели, учитывающие весь комплекс процессов миграции этих радионуклидов в окружающей среде, включая аграрные экосистемы [24, 25].

В 2013 г. при проведении радиоэкологического мониторинга совместно со специалистами АО «Радиевый институт» выполнены оценки накопления органически связанных ${ }^{3} \mathrm{H}$ и ${ }^{14} \mathrm{C}$ в отдельных видах сельскохозяйственной и пищевой продукции района размещения БАЭС и ИРМ (табл. 3). Анализ полученных данных позволил определить схожий характер накопления ${ }^{3} \mathrm{H}$ и ${ }^{14} \mathrm{C}$ в агропродукции. Эти радионуклиды в большей степени накапливаются в кормах сельскохозяйственных животных, чуть менее в продовольственном зерне. Далее по степени накопления трития и углерода-14 следуют молоко и картофель, и в наименьшей степени данные радионуклиды аккумулируются в овощах.

Таблица 3. Содержание органически связанных ${ }^{3} \mathrm{H} u{ }^{14} \mathrm{C}$ в сельскохозяйственной продукиии района Белоярской АЭС в 2013 г., Бк/кг(л)

Table 3. Content of organically bound ${ }^{3} \mathrm{H}$ and ${ }^{14} \mathrm{C}$ in agricultural products in the vicinity of the Beloyarsk NPP in 2013, Bq/kg(L)

\begin{tabular}{|l|c|c|c|}
\hline \multicolumn{1}{|c|}{$\begin{array}{c}\text { Сельскохозяйственная } \\
\text { продусикция }\end{array}$} & $\begin{array}{c}\text { Число проб } \\
\text { Number of } \\
\text { samples }\end{array}$ & ${ }^{3} \mathrm{H}$ & ${ }^{14} \mathrm{C}$ \\
\hline $\begin{array}{l}\text { Ячмень, зерно } \\
\text { Grain of barley }\end{array}$ & 3 & $81,5 \pm 3,5$ & $64,5 \pm 4,8$ \\
Озимая пшеница, зерно & 3 & $40,2 \pm 34,8$ & $48,9 \pm 14,7$ \\
Grain of winter wheat & 3 & $3,2 \pm 1,3$ & $6,1 \pm 4,6$ \\
Кабачки/Zucchini & 2 & $8,7 \pm 4,2$ & $4,1 \pm 0,8$ \\
Капуста/Cabbage & 5 & $28,3 \pm 9,9$ & $18,5 \pm 6,1$ \\
Картофель/Potato & 2 & $5,9 \pm 4,5$ & $4,6 \pm 3,9$ \\
Огурцы/Cucumber & 1 & $5,8 \pm 2,3$ & $8,0 \pm 2,4$ \\
Тыква/Pumpkin & 3 & $193 \pm 23$ & $108 \pm 8,0$ \\
Естественные травы & 2 & $255 \pm 166$ & $82,1 \pm 4,2$ \\
Natural grass & 2 & $10,4 \pm 0,9$ & $95,1 \pm 37,5$ \\
Комбикорм/Animal feeds & \multicolumn{3}{|l}{} \\
Молоко/Milk & \multicolumn{3}{|l}{} \\
\hline
\end{tabular}

Следует отметить, что оценки доз планируемого облучения населения обычно проводятся по радио- 
нуклидам, контролируемым в составе выбросов АЭС в атмосферу. На БАЭС и ИРМ в числе таких радионуклидов рассматриваются: ${ }^{60} \mathrm{Co},{ }^{137} \mathrm{Cs}$, инертные радиоактивные газы, ${ }^{24} \mathrm{Na},{ }^{131} \mathrm{I},{ }^{134} \mathrm{Cs},{ }^{90} \mathrm{Sr},{ }^{54} \mathrm{Mn}$ и ${ }^{51} \mathrm{Cr}$ [7-8]. В связи с отсутствием данных о выбросах ${ }^{3} \mathrm{H}$ и ${ }^{14} \mathrm{C}$, регистрируемых в пробах атмосферного воздуха при радиационном мониторинге района БАЭС и ИРМ вклад этих радионуклидов в дозу планируемого облучения населения не учитывается, что в конечном итоге приводит к некорректной оценке радиационной обстановки в районе размещения данных радиационноопасных объектов. Проблема необходимости обоснования перечня контролируемых в выбросах АЭС радионуклидов требует особого внимания и отдельного изучения. При проведении мониторинговых работ необходимо оценивать все радиологически значимые радионуклиды в составе радиоактивных выбросов и сбросов предприятий ядерного топливного цикла, а также анализировать параметры их миграции в компонентах агроэкосистем и уровень загрязнения сельскохозяйственной и пищевой продукции.

\section{Заключение}

Проведенные исследования показали, что радиоактивность почв сельскохозяйственных угодий 30-км зоны влияния Белоярской АЭС и АО «Институт реакторных материалов» определяется содержанием естественных $\left({ }^{40} \mathrm{~K},{ }^{226} \mathrm{Ra},{ }^{232} \mathrm{Th}\right)$ и техногенных $\left({ }^{137} \mathrm{Cs},{ }^{90} \mathrm{Sr}\right.$ и в некоторой степени ${ }^{239,240} \mathrm{Pu}$ ) радионуклидов. Со-

\section{СПИСОК ЛИТЕРАТУРЫ}

1. Линге И.И., Крышев И.И. Радиоэкологическая обстановка в регионах расположения предприятий Росатома. - М.: САМ полиграфист, 2015. - 296 с

2. Djingova R., Kuleff I. Concentration of caesium-137, cobalt-60 and potassium-40 in some wild and edible plants around the nuclear power plant in Bulgaria // Journal of Environmental Radioactivity. - 2002. - V. 59. - P. 61-73.

3. Analysis of the influence of nuclear facilities on environmental radiation by monitoring the highest nuclear power plant density region / U. Lee, C. Lee, M. Kim, H.R. Kim // Nuclear Engineering and Technology. - 2019. - V. 51. - P. 1626-1632.

4. Радиационно-экологический мониторинг агроэкосистем в зоне воздействия АЭС: методология и результаты исследований / В.К. Кузнецов, Н.И. Санжарова, А.В. Панов, Н.Н. Исамов // Медицинская радиология и радиационная безопасность. - 2019. - Т. 64. - № 4. - С. 25-31.

5. Панов А.В., Исамов Н.Н., Кузнецов В.К. Радиационноэкологический мониторинг в регионе размещения Ростовской АЭС. Анализ результатов многолетних исследований // Радиационная гигиена. - 2019. - Т. - 12. - № 2 (специальный выпуск). - С. 54-65.

6. Анализ результатов радиационно-экологического мониторинга в регионе размещения Курской АЭС / В.К. Кузнецов, А.В. Панов, Н.И. Санжарова, Н.Н. Исамов, Н.В. Андреева, И.В. Гешель, Е.В. Сидорова // Радиационная гигиена. - 2020. T. 13. - № 2. - C. 19-30.

7. Радиационная обстановка на территории России и сопредельных государств в 2013 году. - Обнинск: Росгидромет, 2014. - 357 с

8. Радиационная обстановка на территории России и сопредельных государств в 2018 году. - Обнинск: Росгидромет, 2019. $324 \mathrm{c}$.

9. Методология экологического мониторинга аграрных предприятий в зоне Урала / И.А. Шкуратова, И.М. Донник, А.В. Трапезников, А.Г. Исаева, Н.А. Верещак, А.С. Кривоногова, А.А. Баранова // Аграрный вестник Урала. - 2012. № 2 (94). - C. $60-62$. держание радиоизотопов наведенной активности $\left({ }^{54} \mathrm{Mn},{ }^{59} \mathrm{Fe},{ }^{60} \mathrm{Co}\right)$, а также ${ }^{131} \mathrm{I}$ и ${ }^{134} \mathrm{Cs}$ в почвах агроэкосистем и сельскохозяйственной продукции находилось ниже порога их обнаружения приборами и используемыми методиками измерений.

Результаты радиационно-экологического мониторинга аграрных экосистем также показали, что многолетние газоаэрозольные выбросы Белоярской АЭС и АО «Институт реакторных материалов» не приводят к регистрируемому увеличению содержания техногенных радионуклидов в почве и сельскохозяйственной продукции по сравнению с региональным фоном. При этом отмечено, что состав контролируемых радионуклидов от выбросов БАЭС и ИРМ требует критического анализа, возможного дополнения и совершенствования программ мониторинга. Показана необходимость дальнейшего изучения закономерностей накопления ${ }^{3} \mathrm{H}$ и ${ }^{14} \mathrm{C}$ в сельскохозяйственной и пищевой продукции района размещения АЭС.

Таким образом, радиационно-экологический мониторинг агроэкосистем в зоне влияния Белоярской АЭС должен являться частью комплексного мониторинга всех сред, проводимого на данной территории, на основе которого следует принимать управленческие решения по оздоровлению экологической обстановки в регионе размещения атомной электростанции.

Работа выполнена при поддержке Российского научного фонда (грант № 18-19-00016).

10. Коржавин А.В., Трапезников А.В., Трапезникова В.Н. Методология оценки уровней загрязнения сельскохозяйственных территорий газоаэрозольными выбросами от предприятия ядерного топливного цикла // Ветеринария Кубани. - 2012. № 3. - С. 25-27.

11. Состав, свойства и уровень радионуклидного загрязнения почвенного покрова 15-км зоны Белоярской АЭС / И.В. Молчанова, С.Ю. Кайгородова, Л.Н. Михайловская, Т.Ю. Габерштейн, И.А. Хлыстов // Журнал Сибирского федерального университета. Биология. - 2016. - Т. 9. - № 3. - С. 321-337.

12. Programmes and systems for source and environmental radiation monitoring. Safety report series № 64. - Vienna: IAEA, 2010. - 232 p.

13. Организация государственного радиоэкологического мониторинга агроэкосистем в зоне воздействия радиационноопасных объектов. МУ-13.5.13-00. (утв. Минсельхозом РФ 7 августа 2000 г.) - М.: 2000. -28 с.

14. Determination of plutonium in environmental samples by controlled valence in anion exchange / Q. Chen, A. Aarkrog, S.P. Nielsen, H. Dahlgaard, H. Nies, Y. Yu, K. Mandrup // Journal of Radioanalytical and Nuclear Chemistry, Articles. - 1993. V. $172(2) .-$ P. 281-288

15. Гигиенические требования к безопасности и пищевой ценности пищевых продуктов. Санитарно-эпидемиологические правила и нормы СанПиН 2.3.2.1078-01 // Бюллетень нормативных и методических документов госсанэпиднадзора. - 2002. № 4 (10). - C. 9-144.

16. Санитарно-эпидемиологические правила и нормативы СанПиН 2.3.2.2650-10. (Дополнения и изменения № 18 к СанПиН 2.3.2.1078-01). - М.: Минздрав РФ, 2010. - 13 с.

17. Ветеринарно-санитарные требования к радиационной безопасности кормов, кормовых добавок, сырья кормового. Допустимые уровни содержания $90 \mathrm{Sr}$ и $137 \mathrm{Cs}$. Ветеринарные правила и нормы ВП 13.5.13/06-01 // Ветеринарная патология. -2002 . - № 4. - С. 44-45.

18. Техногенные радионуклиды в почвах и растениях наземных экосистем в зоне воздействия атомных предприятий / Л.Н. Михайловская, В.П. Гусева, О.В. Рукавишникова, 3.Б. Михайловская // Экология. - 2020. - № 2. - С. 110-118. 
19. United Nations, sources and effects of ionizing radiation (Report to the General Assembly with Scientific Annexes). V. 1. Sources. Annex B, Scientific Committee on the Effects of Atomic Radiation (UNSCEAR). UN, New York, 2000. - P. 84-156.

20. Radioactive effluents released from Korean nuclear power plants and the resulting radiation doses to members of the public / T.Y. Kong, S. Kim, Y. Lee, J.K. Son, S.J. Maeng // Nuclear Engineering and Technology. - 2017. - V. 49. - P. 1772-1777.

21. Kotzer T., Trivedi A. Dosimetric implications of atmospheric dispersal of tritium near a heavy-water research reactor facility // Radiation Protection Dosimetry. - 2001. - V. 93 (1). - P. 61-66.

22. Kim C.K., Han M.J. Dose assessment and behavior of tritium in environmental samples around Wolsong nuclear power plant // Applied Radiation and Isotopes. - 1999. - V. 50. - P. 783-791.
23. Exposures of the public and workers from various sources of radiation. UNSCEAR 2016 Report to the general assembly, with scientific annexes. - New York: UNSCEAR, 2017. - P. 135-240.

24. Korolevych V.Y., Kim S.B., Davis P.A. OBT/HTO ratio in agricultural produce subject to routine atmospheric releases of tritium // Journal of Environmental Radioactivity. - 2014. V. $129 .-$ P. $157-168$.

25. Yim M.S., Caron F. Life cycle and management of carbon-14 from nuclear power generation // Progress in Nuclear Energy. - 2006. V. 48. - P. 2-36

Поступила 29.07.2020 г.

\section{Информация об авторах}

Панов А.В., доктор биологических наук, профессор РАН, заместитель директора Всероссийского научноисследовательского института радиологии и агроэкологии.

Tpaneзников A.B., доктор биологических наук, заведующий отделом континентальной радиоэкологии Института экологии растений и животных Уральского отделения РАН.

Кузнецов В.К., доктор биологических наук, главный научный сотрудник лаборатории радиоэкологии и агроэкологического мониторинга Всероссийского научно-исследовательского института радиологии и агроэкологии.

Корж⿻авин A.B., кандидат ветеринарных наук, старший научный сотрудник отдела континентальной радиоэкологии Института экологии растений и животных Уральского отделения РАН.

Исамов Н.H., кандидат биологических наук, ведущий научный сотрудник лаборатории технологий ведения животноводства в условиях техногенного загрязнения Всероссийского научно-исследовательского института радиологии и агроэкологии.

Гешель И.В., научный сотрудник испытательной лаборатории радиационного контроля Всероссийского научно-исследовательского института радиологии и агроэкологии. 
UDC 614.876:504.054

\title{
RADIOECOLOGICAL MONITORING OF AGROECOSYSTEMS IN THE VICINITY OF BELOYARSK NPP
}

\author{
Alexey V. Panov'1, \\ riar@mail.ru
}

\author{
Alexander V. Trapeznikov², \\ vera_zar@mail.ru \\ Vladimir K. Kuznetsov'1, \\ vkkuzn@yandex.ru
}

\author{
Alexander V. Korzhavin², \\ BFS_zar@mail.ru \\ Nizametdin N. Isamov', \\ nizomis@yandex.ru \\ Irina V. Geshel ${ }^{1}$, \\ igeshel@yandex.ru
}

\author{
1 Russian Institute of Radiology and Agroecology, \\ Kiev highway, 109 km, Obninsk, 249032, Russia. \\ 2 Institute of Plant and Animal Ecology, Russian Academy of Science, Ural branch, \\ 202, 8 Marta street, Yekaterinburg, 620144, Russia.
}

The relevance. The release of artificial radionuclides into the environment during NPP operation can lead to their accumulation in separate parts of the trophic chain, which will affect the formation of radiation doses for the members of the public. Agricultural products and local foodstuffs produced near the nuclear power plant are one of the main sources of radionuclides ingestion by humans living in the NPP vicinity.

The main aim of this work was to assess the current radiation situation in the vicinity of Beloyarsk NPP and Research Institute of Nuclear Materials, JSC location based on data from the developed system of radioecological monitoring of agricultural ecosystems.

Objects. Monitoring studies of agricultural ecosystems were performed in 2013 and 2019 in a 30-km zone around radiation-hazardous facilities. 15 control plots on arable lands, 13 control plots on grasslands and 13 control plots on vegetable gardens in the settlements at different distances and directions from these facilities were established there. At the control plots, the dose rate was measured, samples of soil, crops, fodder, food were taken.

Methods. In total, 137 samples were examined in 2013, and 94 samples - in 2019 . The content of ${ }^{40} \mathrm{~K},{ }^{226} \mathrm{Ra},{ }^{232} \mathrm{Th},{ }^{90} \mathrm{Sr},{ }^{137} \mathrm{Cs}$ and ${ }^{239,240} \mathrm{Pu}$ was assessed in the agroecosystems' components. In agricultural and food products, ${ }^{3} \mathrm{H}$ and ${ }^{14} \mathrm{C}$ concentration were additionally measured.

Results. It is shown that the content of ${ }^{90} \mathrm{Sr}$ in the soil of agroecosystems located in the vicinity of radiation hazardous facilities was $4,3 \ldots 7,2 \mathrm{~Bq} / \mathrm{kg}$, and concentration of ${ }^{137} \mathrm{Cs}$ varied within $7,5 \ldots 18,9 \mathrm{~Bq} / \mathrm{kg}$. The range of variation of the content of natural radionuclides was $286 \ldots 432 \mathrm{~Bq} / \mathrm{kg}$ for ${ }^{40} \mathrm{~K}, 16.1 \ldots 21.7 \mathrm{~Bq} / \mathrm{kg}$ - for ${ }^{226} \mathrm{Ra}$ and $20,1 \ldots 25,5 \mathrm{~Bq} / \mathrm{kg}$ - for ${ }^{232} \mathrm{Th}$. The average content of $239,240 \mathrm{Pu}$ in the soil of agroecosystems was $0,13 \mathrm{~Bq} / \mathrm{kg}$ with a variation of $0,07 \ldots 0,25 \mathrm{~Bq} / \mathrm{kg}$. The dose rate was in the range of $0,08 \ldots 0,13 \mu \mathrm{Sv} / \mathrm{h}$, with an average of $0,10 \mu \mathrm{Sv} / \mathrm{h}$. The ${ }^{137} \mathrm{Cs}$ contamination levels of arable land varied within: $1,1 \ldots 3,9 \mathrm{kBg} / \mathrm{m}^{2}$ in 2013 and $1,3 \ldots 2,5 \mathrm{kBq} / \mathrm{m}^{2}$ in 2019 . The range of data on the ${ }^{137} \mathrm{Cs}$ contamination density of grasslands turned out to be wider: $1,5 \ldots . .4,5 \mathrm{kBq} / \mathrm{m}^{2}$ in 2013 and $1,6 \ldots 5,2 \mathrm{kBq} / \mathrm{m}^{2}$ in 2019. The ${ }^{137} \mathrm{Cs}$ contamination densities of vegetable garden soils were within $0,9 \ldots 7,7 \mathrm{kBg} / \mathrm{m}^{2}$. The content of ${ }^{40} \mathrm{~K}$ in the crops produced in the NPP region varied within the range from 48 to $526 \mathrm{~Bq} / \mathrm{kg}$, which is determined by the species' characteristics of plants and the characteristics of the soils where crops are grown. In fodder products, the accumulation of ${ }^{40} \mathrm{~K}$ is noted in the range of $260 . .543 \mathrm{~Bq} / \mathrm{kg}$, in livestock products - in the range of $18 \ldots .97 \mathrm{~Bq} / \mathrm{kg}$. The specific activity of radionuclides in the grain was recorded in the ranges of 1,03...2,8 Bq/ $\mathrm{kg}$ for ${ }^{90} \mathrm{Sr}$ and $0,15 \ldots 0,94 \mathrm{~Bq} / \mathrm{kg}$ for ${ }^{137} \mathrm{Cs}$. The maximum levels of ${ }^{137} \mathrm{Cs}$ accumulation were recorded in barley $(0,94 \mathrm{~Bq} / \mathrm{kg})$ and were 64 times lower than the SanPiN standard. Among vegetables, potatoes and gourds, the maximum levels of the specific activity of both ${ }^{90} \mathrm{Sr}$ $(0,84 \mathrm{~Bq} / \mathrm{kg})$ and ${ }^{137} \mathrm{Cs}(0,26 \mathrm{~Bq} / \mathrm{kg})$ were noted in beets in 2013, but they were below the SanPiN standards in 45 and 300 times, respectively. In cereal straw, the average content of ${ }^{90} \mathrm{Sr}$ varied within $2,3 \ldots 3,6 \mathrm{~Bq} / \mathrm{kg}$, the content of ${ }^{137} \mathrm{Cs}$ was $0,7 \ldots 2,1 \mathrm{~Bq} / \mathrm{kg}$. In the herbage, this range was $1,2 \ldots 3,5 \mathrm{~Bq} / \mathrm{kg}$ for ${ }^{90} \mathrm{Sr}$ and $0,5 \ldots 1,8 \mathrm{~Bq} / \mathrm{kg}$ for ${ }^{137} \mathrm{Cs}$. The maximum levels of the specific activity of ${ }^{90} \mathrm{Sr}$ in straw $(3,6 \mathrm{~Bq} / \mathrm{kg})$ were 50 times lower than the standard for the content of this radionuclide in feeds, for ${ }^{137} \mathrm{Cs}(2,1 \mathrm{~Bq} / \mathrm{kg})$ this difference was 190 times. The maximum levels of content of ${ }^{90} \mathrm{Sr}$ in the grass $(3,5 \mathrm{~Bq} / \mathrm{kg})$ were 14 times lower than the standard, and ${ }^{137} \mathrm{Cs}$ content $(1,76 \mathrm{~Bq} / \mathrm{kg})$ was almost 56 times less. In 2013 and 2019, the dynamics of the content of artificial radionuclides in milk was multidirectional: it slightly increased for ${ }^{90} \mathrm{Sr}$ and decreased for ${ }^{137} \mathrm{Cs}$. However, even the maximum values of the volumetric activity of ${ }^{90} \mathrm{Sr}(0,41 \mathrm{~Bq} / \mathrm{l})$ and ${ }^{137} \mathrm{Cs}$ $(0,11 \mathrm{~Bq} / \mathrm{l})$ in milk turned out to be below the boundary levels established by the SanPiN standards by 60 times for radiostrontium and 900 times for radiocaesium. The measured content of ${ }^{137} \mathrm{Cs}$ in beef $(0,12 \mathrm{~Bq} / \mathrm{kg})$ in 2019 turned out to be more than 1,5 thousand times lower than the requirements of SanPiN. It is shown that ${ }^{3} \mathrm{H}$ and ${ }^{14} \mathrm{C}$ in agricultural and food products accumulate to a greater extent in the feed of agricultural animals (82...255 Bq/kg), slightly less in food grains (40...82 Bq/kg). Further, milk and potatoes (10...95 Bq/kg) follow according to the degree of ${ }^{3} \mathrm{H}$ and ${ }^{14} \mathrm{C}$ accumulation, and to the least extent, these radionuclides are accumulated in vegetables $(3 \ldots 8 \mathrm{~Bq} / \mathrm{kg})$. The results of radioecological monitoring of agroecosystems showed that long-term normalized emissions from Beloyarsk NPP and JSC «Institute of Nuclear Materials» did not lead to a registered increase in the content of artificial radionuclides in soil, agricultural products and food compared to the regional radiation background. The need for further study of the patterns of ${ }^{3} \mathrm{H}$ and ${ }^{14} \mathrm{C}$ accumulation in agricultural and food products of the NPP location area is noted.

\section{Key words:}

Nuclear Power Plant, radiation safety, radionuclides, agricultural products, foodstuffs, radiation control, soil, contamination density. 


\section{REFERENCES}

1. Linge I.I., Kryshev I.I. Radioekologicheskaya obstanovka v regionakh raspolozheniya predpriyatiy Rosatoma [Radioecological situation in the regions where Rosatom enterprises are located]. Moscow, SAM polygraphist Publ., 2015. 296 p.

2. Djingova R., Kuleff I. Concentration of caesium-137, cobalt-60 and potassium-40 in some wild and edible plants around the nuclear power plant in Bulgaria. Journal of Environmental Radioactivity, 2002, vol. 59, pp. 61-73.

3. Lee U., Lee C., Kim M., Kim H.R. Analysis of the influence of nuclear facilities on environmental radiation by monitoring the highest nuclear power plant density region. Nuclear Engineering and Technology, 2019, vol. 51, pp. 1626-1632.

4. Kuznetsov V.K., Sanzharova N.I., Panov A.V., Isamov N.N. Radioecological monitoring of agroecosystems in the NPP vicinity: methodology and results of investigations. Medical Radiology and Radiation Safety, 2019, vol. 64, no. 4, pp. 25-31. In Rus.

5. Panov A.V., Isamov N.N., Kuznetsov V.K. Radioecological monitoring in the vicinity of Rostov NPP. The analysis of results of long-term investigations. Radiation Hygiene, 2019, vol. 12, no. 2 (special issue), pp. 54-65. In Rus.

6. Kuznetsov V.K., Panov A.V., Sanzharova N.I., Isamov N.N., Andreeva N.V., Geshel I.V., Sidorova E.V. The analysis of radioecological monitoring results in the vicinity of Kursk Nuclear Power Plant. Radiation Hygiene, 2020, vol. 13, no 2, pp. 19-30. In Rus.

7. Radiatsionnaya obstanovka na territorii Rossii $i$ sopredelnykh gosudarstv v 2013 godu [Radiation situation on the territory of Russia and neighboring countries in 2013]. Obninsk, Roshydromet Publ., 2014. 357 p.

8. Radiatsionnaya obstanovka na territorii Rossii i sopredelnykh gosudarstv v 2018 godu [Radiation situation on the territory of Russia and neighboring countries in 2018]. Obninsk, Roshydromet Publ., 2019. 324 p.

9. Shkuratova I.A., Donnik I.M., Trapeznikov A.V., Isaeva A.G., Verechak N.A., Krivonogova A.S., Baranova A.A. Metodologiya ekologicheskogo monitoringa agrarnykh predpriyatiy v zone Urala [Methodology of monitoring of agrarian enterprises in the Ural] Agrarian Bulletin of the Urals, 2012, vol. 2, no 94, pp. 60-62.

10. Korzhavin A.V., Trapeznikov A.V., Trapeznikova V.N. Estimation methodology of pollution levels of agricultural territories by gas-airsoles emissions from nuclear fuel cycle enterprises. Veterinaria Kubani, 2012, no. 3, pp. 25-27. In Rus.

11. Molchanova I.V., Kaygorodova S.Yu., Mikhailovskaya L.N., Gaberstein Y.Yu., Khlystov I.A. Composition, property and level of radionuclide contamination of the soil cover within $15 \mathrm{~km}$ zone of the Beloyarsk nuclear power plant. Journal of Siberian Federal University. Biology, 2016, vol. 9, no. 3, pp. 321-337. In Rus.

12. Programmes and systems for source and environmental radiation monitoring. Safety report series № 64. Vienna, IAEA Publ., 2010. $232 \mathrm{p}$.

13. MU-13.5.13-00. Organizatsiya gosudarstvennogo radioekologicheskogo monitoringa agroekosistem $v$ zone vozdeystviya radiatsionno-opasnykh obyektov (utv. Minselkhozom RF 7 avgusta 2000 g.) [MU-13.5.13-00. Organization of state radioecological monitoring of agroecosystems in the zone of exposure to radiationhazardous objects (approved by the Ministry of Agriculture of the
Russian Federation on August 7, 2000)]. Moscow, Ministry of Agriculture of the Russian Federation Publ., 2000. 28 p.

14. Chen Q., Aarkrog A., Nielsen S.P., Dahlgaard H., Nies H., Yu Y., Mandrup K. Determination of plutonium in environmental samples by controlled valence in anion exchange. Journal of Radioanalytical and Nuclear Chemistry, Articles, 1993, vol. 172, no. 2, pp. 281-288.

15. Gigienicheskiye trebovaniya $\mathrm{k}$ bezopasnosti i pishchevoy tsennosti pishchevykh produktov. Sanitarno-epidemiologicheskie pravila i normy SanPiN 2.3.2.1078-01 [Sanitary Rules and Norms 2.3.2.1078-01 Hygienic requirements for food safety and nutritional value]. Bulletin of regulations and methodological documents of the state sanitary and epidemiological supervision, 2002, vol. 4, no. 10, pp. 9-144.

16. Sanitarno-epidemiologicheskie pravila $i$ normativy SanPiN 2.3.2.2650-10. (Dopolneniya i izmeneniya № $18 k$ SanPiN 2.3.2.1078-01) [Sanitary Rules and Norms 2.3.2.2650-10 Additions and changes № 18 to Sanitary Rules and Norms 2.3.2.107801]. Moscow, Ministry of Health of the Russian Federation Publ., 2010. $13 \mathrm{p}$.

17. Veterinarno-sanitarnye trebovaniya $\mathrm{k}$ radiatsionnoy bezopasnosti kormov, kormovykh dobavok, syrya kormovogo. Dopustimye urovni soderzhaniya ${ }^{90} \mathrm{Sr} \mathrm{i}{ }^{137} \mathrm{Cs}$. Veterinarnye pravila i normy VP 13.5.13/06-01 [Veterinary Rules and Norms 13.5.13/06-01 Veterinary and sanitary requirements for radiation safety of feed, feed additives, feed raw materials. Permissible levels of ${ }^{90} \mathrm{Sr}$ and $\left.{ }^{137} \mathrm{Cs}\right]$. Veterinary pathology, 2002, no. 4, pp. 44-45.

18. Mikhailovskaya L.N., Guseva V.P., Rukavishnikova O.V., Mikhailovskaya Z.B. Technogenic radionuclides in soils and plants of terrestrial ecosystems in the zone of impact from nuclear enterprises. Russian Journal of Ecology, 2020, no. 51, pp. 127-135. In Rus.

19. United Nations, sources and effects of ionizing radiation (Report to the General Assembly with Scientific Annexes). Vol. 1. Sources. Annex B, Scientific Committee on the Effects of Atomic Radiation (UNSCEAR). UN, NY Publ., 2000, pp. 84-156.

20. Kong T.Y., Kim S., Lee Y., Son J.K., Maeng S.J. Radioactive effluents released from Korean nuclear power plants and the resulting radiation doses to members of the public. Nuclear Engineering and Technology, 2017, vol. 49, pp. 1772-1777.

21. Kotzer T., Trivedi A. Dosimetric implications of atmospheric dispersal of tritium near a heavy-water research reactor facility. Radiation Protection Dosimetry, 2001, vol. 93 (1), pp. 61-66.

22. Kim C.K., Han M.J. Dose assessment and behavior of tritium in environmental samples around Wolsong nuclear power plant. Applied Radiation and Isotopes, 1999, vol. 50, pp. 783-791.

23. Exposures of the public and workers from various sources of radiation. UNSCEAR 2016 Report to the general assembly, with scientific annexes. New York, UNSCEAR Publ., 2017. pp. 135-240.

24. Korolevych V.Y., Kim S.B., Davis P.A. OBT/HTO ratio in agricultural produce subject to routine atmospheric releases of tritium. Journal of Environmental Radioactivity, 2014, vol. 129. pp. 157-168

25. Yim M.S., Caron F. Life cycle and management of carbon-14 from nuclear power generation. Progress in Nuclear Energy, 2006, vol. 48. pp. 2-36.

Received: 29 July 2020.

\section{Information about the authors}

Alexey V. Panov, Dr. Sc., professor RAS, deputy director, Russian Institute of Radiology and Agroecology.

Alexander V. Trapeznikov, Dr. Sc., head of department, Institute of Plant and Animal Ecology, Russian Academy of Science.

Vladimir K. Kuznetsov, Dr. Sc., chief researcher, Russian Institute of Radiology and Agroecology.

Alexander V. Korzhavin, Cand. Sc., senior researcher, Institute of Plant and Animal Ecology, Russian Academy of Science.

Nizametdin N. Isamov, Cand. Sc., leading researcher, Russian Institute of Radiology and Agroecology.

Irina V. Geshel, research worker, Russian Institute of Radiology and Agroecology. 